\title{
EL DERECHO COMERCIAL Y LA BÚSQUEDA DE UNA TEORÍA JURÍDICA GLOBAL
}

A mi alma mater la

Universidad Nacional Autónoma de México

\section{ALFONSO JESÚS CASADOS BORDE ${ }^{1}$}

\begin{abstract}
RESUMEN: La globalización es un fenómeno que afecta al análisis teórico y práctico del escenario jurídico social, ya que obliga a la reflexión sobre las formas en que dentro de un marco realista socioeconómico se concibe y se aplica el derecho. Pero, para alcanzar esta meta, es necesario obtener una fundamentación que explique la transnacionalización económica del comercio global y su influencia en la creación de normas de manera consuetudinaria, autónoma y periférica, que son adoptadas por el reconocimiento práctico y funcional de los órganos transnacionales, impactando así a la soberanía de las normas formales y centralizadas del Estado nación.

Palabras Clave: Globalización, teoría general del derecho, familias jurídicas, transnacionalización del derecho lex mercatoria, contractualismo global, pluralismo jurídico.
\end{abstract}

ABSTRACT: Globalization is a phenomenon that affects the theoretical and practical analysis of social legal stage, because it forces us to reflect on the ways in which within a realistic socioeconomic framework is conceived and the law applies. But, to achieve this goal, it is necessary to obtain a rationale to explain the economic transnationalization of global trade and its influence on the creation of standards customary, independent and peripheral, which are taken by the practical and functional recognition of transnational bodies, thus impacting on the sovereignty of the formal rules and centralized of the Nation-state.

KEY Words: Globalization, general theory of law, legal family, transnationalisation of law, lex mercatoria (commercial law), global contractarianism, legal pluralism.

\footnotetext{
${ }^{1}$ Profesor de Carrera de la UNAM. definitivo por oposición en el área de derecho mercantil, correo electrónico <alfonso.casados@gmail.com>.
} 
SUMARIO: I. La pretensión de una teoría jurídica general; II. La lex mercatoria como código mercantil global.

\section{LA PRETENSIÓN DE UNA TEORÍA JURÍdicA GENERAL \\ 1. LA GLOBALIZACIÓN Y LA CONCEPCIÓN DE UNA TEORÍA JURÍdICA GLOBAL}

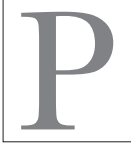

ara algunos tratadistas como lo es Marcos Kaplan, el actual fenómeno de la globalización "se inicia con el origen mismo de la especie humana"; ${ }^{2}$ sin embargo, manifiesta distinciones conceptuales por su cronología y materia entre términos que corren la posibilidad de confundirse como sinónimos. Expresa Kaplan que existe un universalismo filosófico y cultural, ${ }^{3}$ una mundialización de la historia ${ }^{4}$ y una transnacionalización, ${ }^{5}$ diferencian-

${ }^{2}$ Marcos Kaplan, Estado y Globalización, México, UNAM., Inst. Inv. Jur., 2008, p. 17.

${ }^{3}$ Cfr, Marcos Kaplan, Ibidem. "Los avances del universalismo en el pensamiento filosófico y social, de la internacionalización en el pensamiento político, de los proyectos de integración del comercio internacional (regional, continental y mundial), los imperialismos y los colonialismos, las guerras mundiales, podrían ser vistos, entre otras perspectivas, como preliminares de un proceso más comprensivo y penetrante".

${ }^{4}$ Ibid, p. 283: "Con el progreso de la multinacionalizacion de actividades antes internas, el rápido crecimiento de lazos e interrelaciones complejas entre Estados, economías y sociedades, el refuerzo y entrelazamiento de redes de toma de decisiones dentro de marcos mutinacionales, se puede hablar ya del ingreso en la globalización y, con ello, en la mundialización de la historia".

5 Ibid, p. 284: "Con el acceso y el avance de la empresa transnacional (ETN) es a nivel mundial como tienden a constituirse y realizarse los procesos de acumulación e inversión; la concentración y la centralización empresariales; la distribución y escala de sectores, ramas y unidades de la producción; la competencia entre grandes corporaciones. La trasnacionalizacion combina cada vez más los objetivos de maximización de los beneficios a largo plazo; la incorporación y uso de las nuevas tecnologías; el logro de capacidad competitiva a escala mundial (producción en serie, economías de escala, control de mercados, aprovechamiento de un comercio internacional en expansión); el acceso a las reservas de recursos 
do la terminología y analizando las características e implicaciones de la empresa transnacional como factor de poder mundial. ${ }^{6}$

Es en este punto, en donde procede estudiar a las concepciones del fenómeno de la globalización que David Held presenta: La primer concepción, es la que considera la globalización como: "un proceso (o serie de procesos) que engloba una transformación en la organización espacial de las relaciones y transacciones sociales, evaluada en función de su alcance, intensidad, velocidad y repercusión, que genera flujos y redes transcontinental o interregionales de actividad, interacción y de ejercicio del poder". ${ }^{7}$ Y la segunda concepción de este fenómeno, expresa que: "la globalización es un fenómeno multidimensional que involucra diversos dominios de actividad e interacción, incluyendo los dominios económicos, políticos, tecnológicos, militares, jurídicos, culturales y medioambientales. Cada una de estas esferas, involucra diferentes patrones de relaciones y actividades". ${ }^{8}$ Para Gunther Teubner, ${ }^{9}$ estas concepciones son:

[...] el resultado es una multiplicidad de global village autónomas, que despliegan separadamente, en cuanto a ámbitos de función autónomos, una dinámica propia a escala mundial que no resulta controlable desde fuera. Por lo tanto, la globalización no significa sencillamente capitalismo global, sino la realización a escala mundial de la diferenciación funcional. ${ }^{10}$

primarios y mano de obra; en suma, producciones a bajo costo, venta a precios altos, amplios márgenes de lucratividad”.

6 Ibidem.

7 David Held, Anthony McGrew, David Goldblatt y Jonathan Perraton, Transformaciones globales: politica, economía y cultura, México, Oxford University Press, 2002, p. XLIX.

8 David Held, Democracy and the Global Order: From the Modern State to Consmopolitan Governance, London, Polity Press, 1995, p. 62.

9 Profesor de London Schools of Economic and Polititics.

10 Gunther Teubner, Societal Constitutionalism: Alternatives to State-Centred Constitutional Theory?, Oxford, Hart Publishing, 2004, p. 14. 
La globalización se diferencia de la internacionalización porque esta última se concibe como una cooperación entre Estados soberanos, en tanto que la globalización, erosiona la soberanía mediante un proceso de desnacionalización de los mercados, las leyes y la política, interrelacionando pueblos e individuos.

Siguiendo esta línea de reflexión Teubner indica que a la globalización no procede analizarla en el marco conceptual de Immanuel Wallerstein, que ve a la formación de la sociedad global esencialmente como un concepto económico, ${ }^{11}$ porque hay que tomar en cuenta los procesos de globalización autónomos que marchan paralelos a la globalización económica. ${ }^{12}$

La consecuencia de esta etapa de la humanidad en el medio jurídico ha sido la reflexión sobre la búsqueda de una teoría global del derecho aplicable a las diferentes tradiciones, culturas y órdenes jurídicos que por efecto de la globalización se han constituido en un pluralismo legal. Esta configuración jurídica de normas diversas puede considerarse la simiente de un estudio jurídico global.

En este pluralismo concurren una serie de hechos sociológicos que se presentan como irrelevantes para los juristas positivistas propios del derecho Estado-nación, porque éstos estudiosos consideran a la creación jurídica judicial como fuente costumbrista casi única, y la equiparan al derecho consuetudinario. Sin embargo, en la consideración realista socioeconómica, no se considera así; en este punto de observación el derecho consuetudinario privado los hechos sociológicos y económicos son importantes, porque en ellos se desarrollan los usos que se continúan manifestando en los sectores

11 Immanuel Wallerstein, Sistemas Mundo, México, Siglo XXI, 2006, p. 40. Nota sobre la obra: La economía-mundo se presenta en una gran zona geográfica que en ella existe una división del trabajo que no está limitada por una estructura política unitaria.

12 Gunther Teubner, Regímenes Globales Privados: ¿Derecho Neoespontaneo y Constitución Dual de Sectores Autónomos, col. 'Estado Soberanía y Globalización', Bogotá, edit. U. de los Andes y Siglo del Hombre, 2010, p. 65. 
privados, como el comercial, el financiero y el bursátil, y que toman fuerza de reconocimiento jurídico indeterminado en la simple mención de "usos y costumbres", que sin embargo son aplicables en las situaciones no previstas por la ley positiva, creando así un derecho periférico que también debe de considerarse en la propuesta de la teoría global del derecho.

Lo cierto es que se está constituyendo un nuevo orden institucional con una nueva autoridad normativa y una nueva normatividad proveniente del mundo de poder privado que aun así se ubica en la esfera pública, nacional e internacionalmente. ${ }^{13}$ Los poderes hegemónicos resultantes de economía capitalista posterior a la segunda guerra mundial desarrollaron políticas de liberalidad económica que fortalecieron, mediante normas autónomas aplicables para aspectos económicos, prácticas de las empresas transnacionales, como la creación de organismos internacionales financieros como el Grupo del Banco Mundial (The World Bank Group), el Fondo Monetario Internacional (International Monetary Fund), la Organización Mundial del Comercio (OMG) y la Organización para la Cooperación y el Desarrollo Económicos (OECD), que impulsaron la autonomía de los Bancos Centrales de los países como exigencia de obtenciones crediticias y apoyos financieros, y así: "establecer políticas monetarias que son necesarias para impulsar el desarrollo de un mercado global de capitales, y más en general, un sistema económico global". ${ }^{14}$

Los organismos autónomos del poder central del Estado-nación, junto con las empresas transnacionales han creado una nueva normatividad comercial y financiera espontánea y periférica, que se fundamenta, tanto en "usos comerciales", como en "medidas regulatorias", que se ha venido a imponer como normatividad transna-

13 Saskia Sassen, Desnacionalización de las politicas estatales y privatización de la producción de normas, col. 'Estado Soberanía y Globalización', Bogotá, Universidad de los Andes y Siglo del Hombre, 2010, p. 103.

14 Ibidem, p. 115. 
cional globalizadora, necesaria para accionar transacciones, créditos e inversiones, la cual, ha tomado tal relieve que se ha propuesto un constitucionalismo global sin Estado. ${ }^{15}$

\section{A. Distinción entre teoría general del derecho y teoría GLOBAL DEL DERECHO}

Para estudiar una teoría jurídica global es necesario acotar el objeto del estudio y distinguir la teoría jurídica global de la teoría jurídica general. Distinguir entre teoría general del derecho y teoría global del derecho es un ejercicio metodológico básico que William Twining ${ }^{16}$ realiza como en sus trabajos de estudios jurídicos. ${ }^{17}$ Para este tratadista, el concepto de teoría jurídica general es más amplio y flexible que el de teoría jurídica global, ${ }^{18}$ porque la teoría general implica estudios de varias tradiciones, culturas y ordenes jurídicos, o como lo explican sus comentaristas: "observar el derecho en y más allá del mundo entero". ${ }^{19}$

Siguiendo la metodología ya mencionada, para Twining, el término de "filosofía del derecho" resulta restrictivo, porque solamente se refiere al aspecto teórico del derecho, que él denomina "alta teoría" o "high theory"; ${ }^{20}$ y por tal, prefiere utilizar los términos de

15 Gunther Teubner, Globalización y Constitucionalismo Social: alternativas a la teoría constitucional centrada en el Estado, colab. Anuario de la Facultad de Derecho num. 9, trad. Manuel Cancio Melia, Madrid, Universidad Autónoma de Madrid, 2005, p. 203.

16 Profesor emérito de jurisprudencia de University College, London.

17 William Twining, Globalisation and legal theory, London, Butterworths, 2000, p. 12.

18 William Twining, Derecho y Globalización, Bogotá, Universidad de los Andes y Siglo del Hombre, 2003, p. 124.

19 Oscar Guardiola-Rivera, Clara Sandoval Villalba, Un caballero inglés en la Corte del Gran Khan, estudio preliminar, William Twining, Derecho y Globalización, Bogotá, Universidad de los Andes y Siglo del Hombre, 2003, p. 84.

20 Ibidem, p. 53. 
"jurisprudencia” (jurisprudence) y teoría legal (legal theory) para referirse a explicar y ayudar a entender dicha disciplina filosófica. ${ }^{21}$

La globalización ha impactado la relación del orden jurídico nacional con el orden jurídico global, pero, para determinar un estudio de la relación jurídica elemental entre los diversos órdenes jurídicos, es necesario revisar y encontrar una teoría general del derecho que ayude a entender los principios generales del derecho aplicables a un derecho global por encima de las diferentes tradiciones y culturas jurídicas aplicables en una nación o región determinada. ${ }^{22}$

No debe de olvidarse que, en su momento, Jeremy Bentham, realizo estudios de derecho comparado, para buscar una teoría general del derecho. Algunos atribuyen a Bentham ser el cimentador del positivismo analítico británico, ${ }^{23}$ debido a que en su búsqueda por una teoría universal y general del derecho, expuso una crítica al sistema jurídico anglosajón del common law, proponiendo entonces una reforma al mismo, basada en la codificación normativa; ${ }^{24}$ tesis en que, aunada a la tradición del derecho romano germánico, se fundaron los juristas franceses que consideraron e influyeron en el establecimiento de las cinco codificaciones napoleónicas.

La postura de Bentham dentro de las reformas jurídicas que propuso al mundo europeo de su tiempo, tenía como objeto alcanzar el bienestar social y el eudemonismo, mediante un enfoque y aplicación de la maximización utilitarista de la ley.

Conforme a su teoría, habría que distinguir entre "el derecho que es" y "el derecho que debe ser"; en esta distinción, encuentra

21 William Twining, General furisprudence Understanding Law from a Global Perspective, Cambridge, Cambridge University Press, 2000, p. 9.

22 Ibidem, pp. 18-21.

23 Rolando Tamayo y Salmorán, Juris Prudentia: More Geométrico, Dogmática, teoría y metateoría jurídicas, México, Fontamara, 2013, p. 89.

24 Mary Peter Mack, colab. David L. Sills, Enciclopedia Internacional de las Ciencias Sociales, t. I, Madrid, Aguilar, 1979, p. 745. 
que, en "el derecho que debe ser" (censorial law), se encuentran los principios de la teoría general del derecho, fundada en los postulados de la teoría utilitarista. Por otra parte, "el derecho que es" (expository law), contiene la teoría particular del derecho, referida a un orden jurídico en particular, o a un grupo de países con raíces legales comunes.

Los estudios de Bentham recuperaron actualidad en la teoría jurídica británica con el análisis del realismo jurídico norteamericano, debido a que el estudio de la teoría general del derecho se basó en análisis de derecho comparado que el mismo Bentham realizo en sus viajes por Europa, tanto en Francia, como en Alemania, Italia y Rusia, donde vivió años.

La teoría particular del derecho de Bentham se perfila como una visión realista de estudios jurídico-sociales de un orden jurídico; en tanto, que la teoría general del derecho busca transformar la sociedad por medio de la aplicación de un sistema de derecho en varios órdenes nacionales o regionales. De esa consideración de la teoría particular del derecho basada en estudios jurídico-sociales de un orden jurídico, Twining busca una teoría legal global; en tanto que de la aplicación de un sistema del derecho comparado, el mismo Twining pretende que se puede llegar a conformar una teoría general del derecho.

William Twining, en sus estudios, buscando una teoría jurídica general, le da a la globalización un carácter continuado desde dos siglos atrás y apunta que este proceso tiene implicaciones importantes en el mundo del derecho, ${ }^{25}$ porque da a lugar al renacimiento de la discusión sobre la teoría general jurídica. Insiste en que la globalización no es un fenómeno nuevo, ni lo son las relaciones jurídicas transnacionales ${ }^{26}$ el comercio, la diplomacia y el intercambio, han sido transnacionales por siglos y han desarrollado formas útiles de

25 William Twining, Derecho y Globalización, p. 120.

26 Con anterioridad se explicó el sentido de la transnacionalización, que extiende una concepción jurídica hacia uno o varios sistemas jurídicos, pero que no observa toda la variedad de tradiciones, culturas y ordenes jurídicos, así como 
comunicación por lo que es importante recurrir a la teoría jurídica analítica de Bentham, para estudiar ese lenguaje de ese discurso jurídico; en este sentido, reitera que la globalización hace inentendible la legislación local y presenta la necesidad de replantear la naturaleza de toda la teoría jurídica general, ${ }^{27}$ ya que una teoría global del derecho parte de una concepción jurídica transnacional basada en una tendencia de una política económica que se nutre de dos tradiciones jurídicas (romano germánica y anglosajona), que resultan concepciones parroquiales al intentar presentarse como una teoría general e ignorar otras tradiciones y sistemas jurídicos. ${ }^{28}$

\section{LA TEORÍA JURÍDICA GENERAL Y LA GLOBALIZACIÓN}

William Twining, en su trabajo se interesa de manera expresa por la globalización y sus efectos en la teoría jurídica. Explica que la globalización ha impactado a la teoría jurídica tradicional, y ha venido a presentar tres desafíos que si son superados, hay posibilidad de lograr que el derecho se convierta en una disciplina de mayor visión cosmopolita, y alcanzar la idea de una teoría jurídica general, en los términos expuestos por Bentham:

a) El primer desafío, es superar el tratamiento que se da a los Estados-nación, las sociedades, los sistemas jurídicos y los ordenamientos jurídicos, como si fueran entidades cerradas que se puedan estudiar aisladamente, como si fueran "cajas negras";

b) El siguiente desafio, es superar la idea de que el estudio del Derecho o de la teoría jurídica, se puede restringirse a dos tipos de ordenamientos jurídicos: el derecho estatal y el derecho internacional público, entendiéndose este, como relaciones entre Estados-nación; y

hechos sociológicos; en otras palabras, no obtiene una concepción jurídica general, sino que extiende una concepción parcial.

27 William Twining, Derecho y Globalización, pp. 68 y 69.

28 William Twining, General Jurisprudence Understanding Law from a Global Perspective, pp. 18-21. 
c) El último desafío, es superar la insuficiencia y validez del marco y el vocabulario conceptual del discurso jurídico para discutir y explicar fenómenos jurídicos que atraviesan las jurisdicciones, las tradiciones y las culturas.

Para lograr lo anterior, y elaborar un derecho verdaderamente cosmopolita, es necesario recuperar el concepto de la teoría jurídica general, en los términos planteados por Bentham, ya que así, en esta concepción se tienen planteamientos más amplios y flexibles que los que contiene la teoría jurídica global.

Esta teoría global, solamente observa una perspectiva que se manifiesta en una concepción normativa extensiva de uno o dos sistemas jurídicos; en tanto que el concepto de teoría general se refiere al estudio y análisis de dos o más jurisdicciones u ordenamientos jurídicos, y en estas consideraciones en la teoría general, se incluyen estudios que parten desde un nivel micro-comparativo hasta el punto de mayor universalidad jurídica.

Esta concepción de la teoría jurídica general tiene origen en una concepción propia del siglo XIX derivada del análisis de juristas de la tradición jurídica del common law, fundamentalmente derivada de los estudios de Bentham y las concepciones jurídico-analíticas de Austin, en las cuales se distinguía entre la teoría jurídica particular y la teoría jurídica general; la primera se enfocaba a un solo sistema legislativo y la segunda a dos o más sistemas, de tal manera que entonces se conceptuó a la teoría jurídica universal como algo más cercano a que hoy se denominaría teoría jurídica global.

La concepción anglosajona de la teoría jurídica general del siglo $\mathrm{XX}$, mantiene coincidencia con el concepto que de la misma se sostuvo en el siglo XIX, sin embargo, hay diferencias en tres aspectos:

I. La teoría jurídica general del siglo XX se plantea en la problemática de la generalización de los fenómenos jurídicos, la del siglo XIX, no; 
II. La teoría jurídica general del siglo XX se ocupa de todos los niveles del Derecho y no solo del derecho estatal y del internacional público, como lo hacía la teoría del siglo XIX;

III. La teoría jurídica general del siglo XX estudia los fenómenos del pluralismo normativo y jurídico como temas básicos para la teoría jurídica general.

Tomando en cuenta el antecedente anterior, en la tradición jurídica anglosajona, se considera que es en el final del siglo $\mathrm{XX}$, en donde se presentan dos posturas que se enfrentan en su concepción sobre la teoría jurídica general:

1) La teoría jurídica particularista, que tiene un sentido parroquial, según Twining, ${ }^{29}$ acentúa la diferencia entre la concepción teórica del siglo XIX y la del siglo XX, argumentando que la teoría jurídica debe priorizar en su concepción local en el carácter único e irrepetible de la historia, la cultura y la identidad, incluyendo el relativismo cultural y ético; y

2) Por otra parte, se presenta la tendencia en la teoría jurídica que considera que hay una consciencia cada vez mayor de la globalización, que implica el reconocimiento del cambio en la significación de las fronteras nacionales y en la necesidad en que se encuentran, tanto el derecho académico, como la teoría jurídica de tomar en cuenta los niveles múltiples de ordenamiento social y jurídico. ${ }^{30}$

Ambas posturas se antojan insuficientes para alcanzar las metas de universalidad jurídica que pretende la teoría jurídica general, pues, la búsqueda de esta teoría jurídica requiere de un sentido amplio que incluya una panorámica jurídica extensa a los diferentes sistemas, tradiciones y ordenamientos.

Para continuar en busca de la teoría jurídica general, William Twining explica que se debe de acudir al apoyo que presta la teoría jurídica analítica y así determinar los conceptos jurídicos funda-

29 William Twining, Globalisation and legal theory, p. 56.

зо William Twining, Derecho y Globalización, p. 128. 
mentales y universales, que se deban de integrar como parte de una teoría jurídica general y así alcanzar esquemas conceptuales derivados de vocablos especializados más allá de la globalización; esto es, porque en el comercio, la diplomacia y el intercambio, por siglos se han desarrollado formas especiales de gran utilidad en la comunicación global.

Twining también se apoya en la teoría jurídica normativa que estudia las relaciones entre el derecho, la política y la moral, y mediante la misma, teoría, presenta tendencias universalistas de la cultura occidental sobre los valores jurídicos consideradas en el iusnaturalismo, el kantismo y el liberalismo democrático; valores que conecta con la economía de mercado libre y con la democracia, los derechos humanos y el buen gobierno; concluyendo que mediante estas vinculaciones teóricas, es posible alcanzar una teoría jurídica que se pueda considerar intercultural.

Para que una teoría jurídica pueda ser considerada como transnacional y transcultural, deberá tratar el estudio de los valores universales mediante la cuestión de la generalización del razonamiento jurídico (argumentación jurídica), respecto de otros contextos jurídicos, acerca de hechos, políticas, creación de leyes, negociación, etcétera. Para buscar la transnacionalización y transculturización es necesario provocar el renacimiento de la teoría jurídica general. ${ }^{31}$

En la busca de una teoría jurídica general, William Twining estudia las familias jurídicas expresadas en el derecho comparado, y con base en ello, clasifica a las familias ya los sistemas legales. Y es mediante esta clasificación que retoma una investigación realizada en su juventud sobre el Derecho común comparado ${ }^{32}$ y, en este sentido, se adhiere a las tesis que desarrollaron tratadistas como René David, ${ }^{33}$

31 Ibidem. p. 159.

32 William Twining, Cartografiar el Derecho, Derecho y Globalización, Bogotá, Universidad de los Andes y Siglo del Hombre, 2003, p. 182.

33 René David, Grand Systémes de Droit Contemporains, París, Daloz, 1978, y David R. y Jauffret-Spinosi, C., op. cit., p. 13. 
Arminjon, Nolde y Wolf, ${ }^{34}$ en las que concluían que la clasificación de los sistemas legales debería hacerse en "familias".

En este punto, se retoma el estudio de los sistemas jurídicos contemporáneos realizado por René David y la actualización del mismo, que desde el 2002 ha mantenido Camille Jarffret-Spinosi, que expone el análisis comparativo de los sistemas clasificándolos en familias y sistemas:

1. Familia romano-germánica;

2. Familia common law;

3. Familia del antiguo derecho socialista y el sistema jurídico ruso;

4. Sistemas de derecho islámico, indú y judío;

5. Sistemas de derecho del lejano oriente en China y Japón; y

6. Sistemas de derecho de África negra y Madagascar. ${ }^{35}$

En similar tarea es el trabajo de Zweigert y Kötz ${ }^{36}$ que identifican cinco elementos característicos de una familia:

1) Su antecedente histórico y desarrollo;

2) El modo característico predominante de su pensamiento acerca de familias jurídicas;

3) Las instituciones legales especialmente distintivas;

4) Las clases de fuentes legales que conoce y la manera como las maneja;

5) La ideología.

En este marco de estudios de identificación de las familias, cabe mencionar que los referidos Zweigert y Kötz concluyen en un agrupamiento de los grandes sistemas legales del mundo, a los que clasifican en siete partes:

34 Pierre Arminjon, Boris Nolde y Martin Wolf, Traité de Droit Comparé, tomos I, II y III.París, Librairie Generale de Droit el de Jurisprudence, 1950-1951.

35 Ibidem. pp. 12-20.

${ }^{36}$ K. Zweigert y H. Kötz, An Introduction to Comparative Law, London, Oxford University Press, 1997, pp. 69-75. 
1) Familia romanística;

2) Familia germánica;

3) Familia nórdica (escandinava);

4) Familia de derecho común (common law);

5) Familia socialista (hoy postsocialista);

6) Sistemas del lejano oriente (Japón, Corea, China Singapur y Malasia);

7) Sistemas islámicos;

8) Derecho hindú.

En el estudio de la metodología del derecho comparado destaca la observación del jurista mexicano Fix-Zamudio, que expone la aportación de John Henry Merryman ${ }^{37}$ al estudio del mismo derecho comparado al distinguir conceptos entre tradición jurídica y sistemas jurídicos, ya que considera que la tradición jurídica relaciona el sistema jurídico con la cultura, y señala que el sistema jurídico se determina dentro de un ámbito cultural, que se configura en una verdadera tradición jurídica.

Twining se aplica en busca de la nueva teoría jurídica, y toma como apoyo a la obra de Boaventura de Sousa Santos ${ }^{38}$ para explicar una teoría jurídica sobre la globalización que resulta interesante. Para Santos, la teoría jurídica de la modernidad se asocia al positivismo jurídico, el legalismo liberal y la igualación de la "ciencia jurídica" con la dogmática jurídica, y el problema es que la modernidad está en crisis y es remplazada por un paradigma posmoderno que supere las condiciones sociales creadas por la modernidad y el capitalismo.

Para introducirse en esta teoría, Twining considera que se debe de partir desde una postura que Susan Haack" denomina "realista

37 John Henry Merryman, La Tradición Furídica Romano-Canónica, México, Fondo de Cultura Económica, 2004.

38 Boaventura de Sousa Santos, Towards a New Common Sense: Science and Politics in Paradicmatic Transition, London, Routledge, 1995, chapter 7.

39 Susan Haack, Manifiesto of Passionate Moderate (Manifiesto de una moderada apasionada), Chicago, Unversity of Chicago Press, 1998. 
inocente", la cual, Twining reformula con las premisas básicas que se exponen a continuación: la existencia de un mundo real; que este mundo es ampliamente independiente de nuestro conocimiento del mismo; que se acepta que hay muchas descripciones diferentes de la realidad y todas deben de ser compatibles para alcanzar una concepción verdadera; o sea, que conforme al realismo inocente se puede aceptar un relativismo conceptual en las expresiones, sujetas a la conceptualización e interpretación; y que las afirmaciones o conclusiones que se logren pueden tener sentido, pero su valor de verdad es desconocido. ${ }^{40}$

Entonces, es claro que existe un pluralismo, y que en el mundo del Derecho, será un pluralismo jurídico. ${ }^{41}$ Desde una perspectiva realista (o el realismo inocente), el pluralismo jurídico es un concepto y un fenómeno consistente en la coexistencia de múltiples ordenamientos legales y múltiples tradiciones o cuerpos de reglas conceptualizados como hechos sociales dentro de un solo sistema jurídico. ${ }^{42}$

Debido a los efectos de la globalización, al estudiar los diferentes sistemas jurídicos, los juristas se han tomado consciencia de la condición multicultural y pluralista de las sociedades y se ha reconocido que éstas en la actualidad, tienen que adecuarse globalmente para reconocer y reforzar las diversas normas compatibles en las religiones, culturas o tradiciones. Así se conforma el pluralismo jurídico de Estado que es reconocido mundialmente, ${ }^{43}$ aclarando que esta acepción es regularmente más asociada con un derecho consuetudinario o "no estatal", que con el derecho positivo.

El pluralismo jurídico, de acuerdo con Santos, se ha desarrollado en la cotidianidad como experiencia e incluye el concepto de inter-legalidad, porque la humanidad actualmente experimenta un

40 William Twining, Globalisation and legal theory, pág. 206.

41 Ibidem, p. 205.

42 Ibidem, p. 224.

43 John Griffiths, "Whath is Legal Pluralism?", London, fournal of Legal Pluralism, Núm. 24, I, Routhledge, 1986, pp. 1-55. 
pluralismo normativo que le obligará a desarrollar una nueva teoría jurídica general que replantee el derecho desde una perspectiva global, para lo cual se identifican siete tipos de transnacionalización legal:

1) Transnacionalización del derecho del Estado, armonizando, ajustando y unificando las ramas del derecho a lo condicionado y señalado por el Banco Mundial (The World Bank Group) y el Fondo Monetario Internacional (FMI);

2) Desarrollo de regímenes jurídicos de integración regional, como la Unión Europea;

3) Regulación comercial transnacional, como lo es la lex mercatoria;

4) Leyes de personas en constante peregrinación (Law of People on the Move), refiriéndose a los migrantes, refugiados desplazados;

5) Derecho de los pueblos indígenas derivados del reconocimiento de antiguos agravios y nuevas solidaridades;

6) Temas cosmopolitas y derechos humanos; y

7) Herencia común de la humanidad, como la Ley del Mar, el Tratado de la Luna y el patrimonio cultural de la humanidad (Ius humanitatis). ${ }^{44}$

Para Santos, resulta claro que los primeros tres tipos están ligados al capitalismo global o neoliberalismo y que los cuatro últimos lo están a las legalidades cosmopolitas, anti-hegemónicas y utópicas, por lo que son puntos de atención al respecto.

Es por eso, que, tanto, Santos, como Twining, utilizan el "mapeo jurídico" como método de determinación de la pluralidad de la teoría global del Derecho.

44 William Twining, Globalisation and legal theory, pp. 239-241. William Twining, Derecho y Globalización, pp. 283-285. 
II. LA LEX MERCATORIA COMO CÓdIGO MERCANTIL GLOBAL

\section{El derecho contractual global}

Concluye Twining en que la globalización de los sistemas social, económico y jurídico ha interrelacionado a los humanos en un sentido realista y funcional, por lo cual se han desarrollado nuevas y diversas formas de manifestar una nueva modalidad del ejercicio del sistema jurídico. En este sentido, es de observarse que el derecho contractual comercial tiene una actuación global muy relevante, misma que marca la pauta de las nuevas relaciones jurídicas que interactúan con los las estructuras legales de los Estados nacionales, provocando incluso conflictos de soberanía y flexibilizaciones normativas.

Este derecho contractual global se ha venido a incrustar en el derecho internacional dentro de los Principios UNIDROIT del Instituto Internacional para la Unificación del Derecho Privado apoyado por la Comisión de las Naciones Unida para el Derecho Mercantil Internacional, que esencialmente no son más que los principios generales del derecho de los contratos. ${ }^{45}$ También se puede mencionar a los Principios Trans-Lex dictados en el año 2009 por el Centro de Derecho Transnacional (GENTRAL) de la Universidad de Colonia, Alemania ${ }^{46}$ como una plataforma de búsqueda y codificación en línea que contienen ciento veintiocho (128) reglas y principios de la Nueva Lex Mercatoria (NLM). En el mismo sentido y aún más, se manifiesta la resolución numero A/C.6/60/L.7 de la Convención de la Sexta Comisión de la Organización de las Naciones Unidas, aprobada por la Asamblea

45 Pedro Alfonso, Labariega Villanueva, Los Principios UNIDROIT: un código internacional de los contratos mercantiles, <http://www.juridicas.unam.mx/publica/ librev/rev/revdpriv/cont/25/dtr/dtr2.pdf>, [última consulta, 9 de septiembre de 2015].

${ }^{46}$ Disponible en: <http://www.trans-lex.org/principles/pdf/>, [última consulta, 9 de septiembre de 2015]. 
General el 9 de noviembre del año de 2005, para el uso de las comunicaciones electrónicas en los contratos internacionales. ${ }^{47}$

Así, las empresas que se expanden en la globalización, convergen y promueven la aplicación de nuevas instituciones jurídicas para su ejercicio comercial. De esta manera, la globalización ha desarrollado, en base a aspectos comerciales, alianzas internacionales, mercados comunes y organizaciones comerciales variadas; y también ha desarrollado, desde la remota antigüedad, normas internacionales en materia mercantil, como lo ha sido y es, la Lex Mercatoria; la cual, actualmente se ha retomado como modelo de referencia de los principios generales del Derecho Comercial; además, de que se han promovido principios generales de derecho privado para la unificación internacional legislativa de las instituciones y figuras del derecho mercantil. ${ }^{48}$

Todo este contexto en que la globalización comercial se desenvuelve contiene una consideración jurídica sobre la que hay que tomar nota. Hay otro aspecto de la sistemática jurídica de la globalización de la posmodernidad postindustrial que está muy vinculado a las actividades comerciales de ésta nueva era de desarrollo tecnológico: La comercialización se desenvuelve mediante la electrónica informática; y es el comercio electrónico por medio del cual se está desarrollando ampliamente la actividad mercantil moderna, lo cual, obliga a determinar las vinculaciones del sistema jurídico revitalizado denominado Lex Mercatoria con el otro sistema jurídico postindustrial globalizado denominado Lex Informática.

Por esa razón se tienen que estudiar y determinar las consecuencias jurídicas del uso y tráfico de las redes del ciberespacio, o

47 Faye Fangfei Wang, Law of electronic commercial transctions, Oxon, RN, Routledge, 2a. ed. 2014, pp. 309-319. <http//daccess-dds-ny.un.org/doc/UNDOC/ GEN/NO5/578/61/PDF/NO557861.pdf?OpenElement>, [última consulta, 10 de julio de 2015].

48 Wyndham Beawes, Lex Mercatoria: A complete Code of Commerce, London, London, F.G.and J.Rivington, 1813, pp. 1-3. 
sea, del internet; de tal manera que se está dando lugar a una nueva concepción de la regulación jurídica que algunos llaman el ius retis: el Derecho de las redes del ciberespacio o Lex Informática, que tiene una importancia similar a la de la Lex Mercatoria. ${ }^{49}$

Entre los tratadistas se debate afirmando y otros negando que la antigua Lex Mercatoria consistiera en un verdadero sistema ${ }^{50}$ jurídico; mas, por lo que toca a la actual concepción, es un conjunto de normas, principios, reglas que están autorganizándose,${ }^{51}$ por lo que se considera un verdadero sistema jurídico abierto. Entre los que reconocen su carácter jurídico se han escindido en dos tesis: La tesis positivista, que considera que la Lex Mercatoria tiene un origen internacional y solo existe en función de que algunos Estados la reconocen y ratifican su validez en función de tratados e instrumentos internacionales; y la otra tesis, que es la autonomista, que concibe a esta Lex como un sistema auto generador de reglas destinadas creadas en actuaciones comerciales no gubernamentales por y para la comunidad internacional de comerciantes. ${ }^{52}$ Entre los autonomistas se encuentran tratadistas como Klaus Peter Berger, que en su obra The Creeping Codification of the New Lex Mercatoria ${ }^{53}$ siguiendo la tradición de la obra de Beawes, Wyndham, en su libro clásico Lex Mercatoria: A complete Code of Commerce, editado en 1813, considera a la Lex Mercatoria como un derecho transna-

49 Ernesto Grün, Una visión sistemática y cibernética del derecho en el mundo globalizado del siglo XXI, Buenos Aires, Arg. Lexis Nexis, 2006, p.116.

50 Conjunto de reglas o principios sobre una materia racionalmente enlazados entre sí. Real Academia Española, Diccionario de la Lengua Española, Madrid, edit. Espasa Calpe, t II, p. 1888.

51 E. Grün, op. cit., p. 114.

52 Sara Feldstein de Cárdenas, Contratos internacionales, 3". parte: "Lex mercatoria", Buenos Aires, Abeledo-Perrot, 1995, pp. 205-207.

53 Klaus Peter Berger, The Creeping Codification of the New Lex Mercatoria, Frederick, MD, Wolters Kluwer, 2010, p. 410. 
cional $^{54}$ que implica un desprendimiento o falta de referencia a un derecho nacional. ${ }^{55}$

Para estos estudiosos, la Lex Mercatoria incluye principios generales de Derecho relacionados con el comercio internacional, que si bien se vinculan a los principios generales de la filosofía del derecho, estos principios son propios de la Lex en mención y difieren de los principios generales, por tener un mayor contenido de carácter subjetivo mercantil (ya que es un derecho especial para comerciantes).

Se destacan dentro de los mismos principios, los siguientes: pacta sunt servanda, actor incubit probatio, ut res magis valeant quam pereat, exceptio non adimpleti contractus, buena fe en el cumplimiento de las obligaciones contractuales, necesaria limitación de daños, prohibición de enriquecimiento injusto, reconocimiento de causas de fuerza mayor, etcétera. ${ }^{56}$ En una ratificación de los principios mencionados se presentan los Principios Trans-Lex de la Universidad de Colonia, Alemania $^{57}$ con sus ciento veintiocho (128) reglas y principios que fortalecen la Nueva Lex Mercatoria (NLM).

Es imposible tratar este tema de los principios comunes del derecho privado, sin tomador en consideración que desde 1971 el grupo de profesores de derecho comparado, encabezados por René David, Glive M. Schmitthoff y Tudor Popescu, crearon el Instituto Inter-

54 La transnacionalidad es la noción que define y engloba lo que excede el marco de una nación. Esta noción está fundamentalmente ligada al fenómeno de la mundialización. En tanto, lo internacional es referente a dos o más nacionas.

55 Klaus Peter Berger, Transnacional Commercial Law in the Age of Globalization, Saggi, Roma, Conferenze e Seminari 42. Reproduced with permission of Centro di studi e ricerche di diritto comparator e straniero, 2001, p. 17, <http:// cisgw3.law.pace.edu/cisg/biblio/berger1.html 9 X2011>, [última consulta, 9 de septiembre de 2015].

56 Jorge Alberto Silva Silva, Resurgimiento de la Lex Mercatoria: La regulación de las relaciones comerciales internacionales, colaboración para Estudios sobre 'Lex Mercatoria. Una realidad internacional', México, edit. Instututo de Investigaciones Jurídicas, UNAM., 2006, p. 258.

57 Disponible en: <http://www.trans-lex.org/principles/pdf/>, [última consulta, 9 de septiembre de 2015] . 
nacional Para la Unificación del Derecho Privado (UNIDROIT) y desarrollaron, el restatement internacional del marco referencia de los principios generales del derecho de los contratos, partiendo de la simbiosis de todas las tradiciones y sistemas jurídicos tales como el romano germánico, el common law y el postsocialista, para así establecer un cuerpo de reglas funcionales en todo el mundo, independientemente de la tradición o sistema jurídico en sean originadas y vigentes. ${ }^{58}$

En el Preámbulo del Documento Constitutivo del Instituto Internacional Para la Unificación del Derecho Privado (UNIDROIT) donde se explica el propósito de los principios que se exponen, se menciona el siguiente concepto: "Estos Principios pueden aplicarse cuando las partes hayan acordado que su contrato se rija por principios generales de derecho, la "lex mercatoria" o expresiones semejantes. ${ }^{59}$

De hecho, los principios UNIDROIT se han convertido en el derecho de los contratos referente de toda la contratación internacional y siempre son referidos en las disputas arbitrales comerciales, tanto internacionales, como locales.

Reconsideraciones jurídicas, respecto de sus características y peculiaridades especiales por ser un conjunto de reglas de formación consuetudinaria, con influencia de la práctica comercial marítima griega, ${ }^{60}$ reconocidas contractualmente por los comerciantes implicados en transacciones y disputas sobre las mismas operaciones mercantiles.

58 René David y Camille Jauffret-Spinosi, Los Grandes Sistemas Furídicos Contemporáneos, trad. Jorge Sánchez Cordero, México, Instituto de Investigaciones Jurídicas UNAM, 2010, p. XIV.

59 Instituto de Investigaciones Jurídicas, UNAM, y el Instituto Internacional para la Unificación del Derecho Privado, Principios UNIDROIT sobre los contratos comerciales internacionales 2004, Roma, Instituto Internacional para la Unificación del Derecho Privado y la UNAM, 2007, p. 1.

60 Friedrich K. Juenger, The Lex Mercatoria and private international law, Oxford, Oxford Journals, 'Uniform Law Review', issue 1 2000, p. 172. 
Para algunos tratadistas, como Rene David, la Lex Mercatoria, se allá de las leyes de carácter nacional, o del derecho internacional público, porque no es el resultado de una convención gubernamental de carácter internacional, sino que consiste en una auténtica normatividad privada multilateral, a la que se adhirieren gremios comerciales y mercaderes en lo individual. Sin embargo, por lo que toca a la Nueva Lex Mercatoria, dada su evolución, si se le puede considerar como un conjunto de reglas transnacionales de derecho internacional privado, por estar integrada al cuerpo dispositivo de la Organización de las Naciones Unidas; lo cual, otorga un sentido positivista a esta disposición. ${ }^{61}$

\section{TeORía JuRídica de La globalización MERCANTIL}

La globalización ha provocado una inercia económica que ha impactado en las instituciones del derecho privado comercial enfocándolo como norma transnacional derivada de las aplicaciones contractuales. De esta manera, la globalización se recicla autopoiticamente mediante el carácter esencial de la relación jurídica mercantil: El contrato

La contratación internacional, por parte de sujetos comerciales, consistentes, tanto las empresas gubernamentales, las empresas sociales, y las privadas, ha logrado configurar una autentica normatividad globalizada que se ha venido a plasmar en los dos cuerpos normativos básicos del derecho comercial transnacional que son: los principios UNIDROIT y la Lex Mercatoria.

Las operaciones comerciales se han incrementado en el plano transnacional, contemplando como derecho de fondo de las mismas a diferentes normas jurídicas vigentes en distintas naciones; y también, dichas operaciones toman fundamento en las disposiciones del derecho comercial transnacional antes mencionadas; pero además,

61 Klaus Peter Berger, The Creeping Codification of the New Lex Mercatoria, Frederick, MD, Wolters Kluwer, 2a. 2010. pp. 1-14. 
cabe señalar que de manera continua se utilizan los usos comerciales, bancarios y bursátiles, de manera autónoma conforme a la voluntad de las partes.

La globalización del derecho mercantil configurado dos rasgos característicos propios de esta rama jurídica: la subjetivización de la misma por ser una normatividad especial para sujetos comerciales, y que dada la necesidad de que esta rama jurídica se adaptara a la realidad socioeconómica, las normas deben tomar una posición congruente al realismo ya mencionado y tomar un carácter excepcional a algunas normas e instituciones del derecho civil, distinguiéndose en grado, mas no en esencia de esta otra rama del derecho privado y por consecuencia, deslindando su autonomía en sus reglas de aplicación.

Los sujetos del derecho mercantil globalizado son los identificados como comerciantes ubicados en las ramas básicas del derecho: El derecho público, el privado y el social.

Esta normatividad comercial a que ha dado lugar la globalización económica no ha desarrollado de manera sistemática una correspondencia ajustable a la doctrina positivista formalista, debido a que las mismas circunstancias de ajuste práctico a la realidad socioeconómica que se ha presentado entre esta corriente jurídica autónoma y espontánea, toma distinción con el derecho internacional, que se desarrolla con reglas especiales de convenios de cooperación y de sanciones de coercibilidad laxa, que requieren de otras fórmulas normativas para acoplar su dinámica, en este caso la comercial a un sistema jurídico que le sea práctico y satisfactorio a sus fines.

En el derecho internacional positivo de la globalización, los Estados nacionales dan lugar a la creación de normas jurídicas mediante convenios, acuerdos y tratados internacionales comerciales, mismos que en su normatividad siguen las características y consideraciones especiales que impone el realismo socioeconómico en las normas especiales para comerciantes excepcionales al excesivo formalismo del derecho civil; o según el caso, se reconocen normas jurídicas emitidas por un 
ente internacional al que los Estados se encuentran adheridos en alianza, liga, o unión de carácter comercial.

En estos puntos de estudio sobre la pluralidad jurídica y la transnacionalización legal globalizada, es claro que una de las transnacionalizaciones legales es de carácter comercial que parte del convenio comercial consuetudinario. Este derecho mercantil consensual es una de las características originales de este derecho que se expresa en la lex mercatoria, que está basada en aspectos de realismo socioeconómico. Así que, como lo explican Twining y Boaventura de Sousa Santos, sí existe una teoría aplicable a la globalización mercantil, que resulta ser el realismo jurídico socioeconómico, teoría que, participa de manera incluyente en la generación de la nueva teoría general jurídica de la globalización.

En este sentido, el derecho mercantil de la globalización parte de un derecho consuetudinario que se presenta en la periferia del sistema legal y "surge de procesos a largo plazo de comunicación difusa y de la integración recursiva, que constituye un tipo dominante de creación de normas jurídicas, particularmente en las sociedades tradicionales". ${ }^{62}$

La globalización económica trajo consigo a la jurídica y ésta tomó fundamento en la teoría del realismo socioeconómico, que por su ejercicio práctico, ágil y sin exceso formal, desplazó al positivismo jurídico centralizado de hegemonía operativa socioeconómica actual, como lo explican las tesis de Capella ${ }^{63}$ y Faria. ${ }^{64} \mathrm{La}$ globalización se ha constituido en el fenómeno objeto de análisis en la actualidad, y como concepto integrador incluye varios estudios

62 Gunther Teubner, Regímenes Globales Privados: ¿Derecho Neoespontáneo y Constitución Dual de Sectores Autónomos?, p. 76.

63 Juan Ramón Capella, Fruta Prohibida, 3 ${ }^{\text {a }}$. ed., Madrid, Trotta, 2001, pp. 249 y 273.

64 José Eduardo Faria, El Derecho en la Economía Globalizada, Madrid, Trotta, 2001, pp. 364-365. 
de diversos campos, tocando en lo jurídico a tratadistas que exponen nuevos enfoques y reflexiones.

En la globalización jurídica se desarrolló una nueva normatividad privada originada por la autonomía de organismos internacionales, instituciones financieras y bursátiles transnacionales y empresas privadas también transnacionales de carácter comercial, financiero, bursátil, de servicios legales,${ }^{65}$ de estándares de calidad, contabilidad, de información comercial y financiera, y de gobierno corporativo; independientemente de la normatividad sobre contratación comercial, arbitraje comercial, comercio electrónico, transferencia de fondos, todos desarrollados por Organizaciones No Gubernamentales.

Este fenómeno influyo en la Organización de las Naciones Unidas, en donde la Asamblea General estableció por resolución número 2205 (XXI) de fecha 17 de diciembre de 1966, la Comisión de las Naciones Unidas para el Derecho Mercantil Internacional (CNUDMI, o UNCITRAL en inglés), la cual ha establecido Leyes Modelo para diferentes aspectos de interés en esta comisión. De tal forma, que se han dictado leyes para el arbitraje comercial internacional (1985 y 2006), sobre comercio electrónico (1996), sobre firmas electrónicas (2001), sobre transferencias internacionales de créditos (1992), sobre contratación pública de bienes, de obras y de servicios (1993, 1994, y 2011), y sobre insolvencia transfronteriza (1997); así también, se han dictado guías jurídicas de contratos internacionales de construcción de instalaciones industriales (1987), de operaciones de comercio compensatorio (1992) y de transferencias electrónicas de fondos (1987).

El derecho mercantil de la globalización jurídica se ha destacado por formar una normatividad internacional convencional y consuetudinaria expresada en disposiciones como la Lex Mercatoria, las UCP 600 y los INCOTERMS 2011; por otra parte, la normatividad positiva del derecho privado y público, dada su rigidez y

65 Saskia Sassen, op. cit., p. 128. 
exceso formalista, es desplazada por la globalización transnacional que impone sus efectos en la necesidad de los países de adecuarse a la apertura económico-comercial, y sufre el ajuste, modificación y flexibilización para adecuarse a las mencionada normatividad, que marcan las nuevas reglas y los usos comerciales internacionales.

La otra fuente de la globalización jurídica comercial, consiste en la nueva regulación mercantil internacional derivada de los tratados y convenios comerciales suscritos entre los diversos países. Estos tratados comerciales han enriquecido a las legislaciones de los países que incorporan estos convenios y tratados a su derecho positivo, en virtud de las disposiciones constitucionales de los mismos, que otorgan la categoría de ley a los tratados internacionales que dicho país suscribe.

Todas estas nuevas manifestaciones que la globalización ha presentado ante el derecho mercantil de los distintos países, tienen como fuente originaria la relación contractual comercial de los comerciantes, ya sean éstos de carácter público, o de tipo privado, que son referidos por Francis Fukuyama ${ }^{66}$ y Niklas Luhman ${ }^{67}$ en sus estudios sobre el valor de la confianza como capital social de las relaciones económico-sociales, y que es un elemento fundamental de la certeza con que se puedan desarrollar las transacciones comerciales, el progreso, el respeto al derecho y la paz social.

Cabe concluir entonces, que el derecho mercantil globalizado es un elemento de avanzada en el desarrollo de una teoría global del derecho, y por consecuencia, en la búsqueda de una teoría general del derecho. Como se ha expuesto, la teoría global del derecho se ha desarrollado fundamentalmente mediante la acción transnacional realista socioeconómica del derecho mercantil, que ha partido de una emisión normativa de carácter privada de organismos autónomos diferenciados de la normatividad central del Estado nación.

\footnotetext{
66 Francis Fukuyama, La Confianza, Barcelona, Sine qua non, 1998, p. 47.

67 Niklas Luhmann, Confianza, Barcelona, Antropos, 2005, pp. 86-87.
} 
A su vez, el derecho mercantil se ha manifestado como elemento integrador del pluralismo jurídico que incluye la observancia de las diferentes tradiciones, sistemas y ordenes jurídicos; además de considerar los hechos socioeconómicos de las anteriores expresiones, para así intentar integrarse a lo pretendido por una teoría general del derecho, dentro de las consideraciones de Twining. 